\title{
Uma Análise da Evasão Escolar nos Cursos de Tecnologia da Informação: Um estudo de caso em Floresta/PE
}

\author{
Everton Eugênio de Oliveira Silva ${ }^{1,2}$, Josilaine de Souza Silva ${ }^{1,2}$, Cassiano \\ Henrique de Albuquerque ${ }^{1,2}$
}
${ }^{1}$ Grupo de Pesquisa em Inovações Tecnológicas na Gestão de Hardware, Software e Peopleware - GITEG
${ }^{2}$ Instituto Federal de Educação Ciência e Tecnologia do Sertão Pernambucano Caixa Postal 56400-000 - Caetano II - Floresta - PE - Brasil
evertonenew@gmail.com, josylayne.silva@gmail.com, cassiano.henriquedifsertao-pe.edu.br

\begin{abstract}
School dropout in information technology courses, directly affects economy and cultural development at any society. Interruption in the schooling process affects economy because it results in shortage of skilled labor, which hinders regional economic development. In order to address this issue, the Brazilian government has outlined goals to reduce this phenomenon, which is even more pronounced at Sertão Nordestino. This paper presents a qualitative and quantitative research on school dropout rates in information technology courses at Instituto Federal do Sertão Pernambucano no Campus Floresta, indicating possible solutions to this issue.
\end{abstract}

Resumo: A evasão escolar nos cursos de tecnologia da informação, afeta diretamente a economia e o desenvolvimento cultural de qualquer sociedade. A interrupção no ciclo escolar afeta a economia, pois resulta em escassez de mão-de-obra qualificada, o que dificulta o desenvolvimento econômico regional. Para tratar deste problema, o governo brasileiro tem traçado metas para atenuar este fenômeno, que é ainda mais acentuado no Sertão Nordestino. Este artigo expõe de forma qualitativa e quantitativa os índices de evasão escolar nos cursos de tecnologia da informação do Instituto Federal do Sertão Pernambucano no Campus Floresta, apontando possíveis soluções atenuadoras para esta problemática tão relevante.

\section{Introdução}

A evasão é um fenômeno social complexo, definido como interrupção no ciclo de estudos [GAIOSO, 2005]. A evasão escolar é um tema muito pertinente ao ambiente acadêmico, em vários países este tema requer maior atenção por ter um índice muito alto de evasão escolar. A evasão estudantil afeta os resultados dos sistemas educacionais e a economia pública e privada, pois resulta em escassez de mão-de-obra qualificada 
impedindo assim o desenvolvimento econômico de forma mais efetiva. Outro problema bastante relevante que a evasão escolar traz é a ociosidade de professores, espaço físico e equipamentos.

O Relatório de Auditoria do Tribunal de Contas da União resultante do Processo $n^{\circ}$ 026.062/2011-9 [TCU, 2013], realizado com vistas a avaliar as ações de estruturação

e expansão da Rede Federal de Educação Profissional, Científica e Tecnológica, encontrou uma taxa de evasão nos cursos Médios Subsequentes de 19\%, utilizando os dados do Sistema Nacional de Informações da Educação Profissional e Tecnológica (SISTEC), para os ciclos de matrícula iniciados a partir de 2004 e encerrados até o primeiro semestre de 2011, nos Institutos Federais do Espírito Santo, Rio Grande do Sul, Rio de Janeiro, São Paulo, Minas Gerais, Pernambuco, Sertão Pernambucano, Goiás e Rio Grande do Norte. No Termo de Acordo de Metas e Compromissos que a Secretaria de Educação Profissional e Tecnológica (SETEC/MEC) celebrou com cada um dos Institutos Federais foi definido um Índice de Eficácia da Instituição, calculado pela média aritmética da eficácia de cada turma, medida pela relação entre o número de alunos concluintes e o número de vagas ofertadas no processo seletivo para cada uma dessas turmas, sendo a meta mínima de $80 \%$ de eficácia da Instituição no ano de 2016, com meta intermediária de, no mínimo, $70 \%$ no ano de 2013. Uma taxa elevada para esse índice significa que os investimentos realizados pelos Institutos Federais, em infraestruturas, professores e técnicos, estão gerando produtos (alunos concluindo cursos) em número satisfatório.

\section{O Problema da Evasão no Ensino Superior}

A evasão estudantil no ensino superior é um problema internacional que afeta o resultado dos sistemas educacionais. [SILVA FILHO, 2007]. Além de afetar os resultados dos sistemas educacionais, um índice de evasão escolar acima do esperado afetará também o desenvolvimento social.

Vários fatores podem ser elencados como condicionantes da crise da educação brasileira em relação a evasão escolar, tais como: crescimento desordenado no número de instituições de ensino; problemas de ordem orçamentária nas públicas; descompasso entre as pesquisas produzidas e as demandas da sociedade; descontinuidade $\mathrm{e}$ fragilidade dos programas de ensino e pesquisa; currículos fragmentados, defasados, sem interdisciplinaridade e pouco flexíveis; corporativismo muito forte em todas as classes/níveis nas instituições de ensino; a estrutura do poder ainda centralizadora e conservadora [KINPARA e DAN, 1995].

Assim, de acordo com Kinpara e Dan (1995), enquanto a técnica existir dissociada do homem que a usa, de um contexto histórico, entendida como sistema estático, que não se adapta, não se modifica, apenas reativo, e não ativo, não será possível compreender a realidade e muito menos se definir diante dela. Milléo et al. (2000) reforçam este pensamento, quando afirmam que o profissional formado dentro 
de uma perspectiva tecnicista e pessimista, dentro e fora de um meio acadêmico, sofre os reflexos manifestando grande insegurança e dificuldade em tratar com diferentes segmentos da sociedade.

Sob esse aspecto, esta pesquisa tem a intenção de atender a duas esferas designadas: a primeira de ordem institucional e a segunda esfera decorrente do aspecto social. Como princípio, esta pesquisa atende ao aspecto institucional ao contribuir para a academia com o estudo na linha de pesquisa de economia regional, enfatizando uma dimensão social, política e econômica nas instâncias da educação técnica / superior , contribuindo, dessa forma, para o avanço dos estudos sobre fenômenos sociais e suas manifestações regionais. A segunda esfera deste projeto atende ao crescimento da demanda social por educação técnica / superior, demanda na qual os trabalhadores buscam refúgio para o enfrentamento de um problema de mudança social que configura mudança no aspecto social [CASTEL, 1998].

Silva Filho (2007) define dois aspectos similares, mas não idênticos: evasão anual, que verifica a diferença entre alunos matriculados de um ano para o outro, e a evasão total, ao comparar o número de alunos matriculados com o número final de alunos concluintes do curso.

\subsection{O Problema da Evasão nos Institutos Federais}

A Rede Federal de Educação Profissional, Científica e Tecnológica atua na capacitação de diferentes segmentos da mão de obra nacional. Seus cursos variam desde modalidades de curta duração, como os cursos de formação continuada e inicial, em que são requeridos apenas níveis fundamentais de educação, até cursos de mestrado. Conforme estabelecido no Art. $7^{\circ}$, incs. III e IV da Lei 11.892/2008, além de ministrar cursos profissionais, fazem parte dos objetivos da Rede Federal: realizar pesquisas aplicadas, estendendo seus benefícios à comunidade; e desenvolver atividades de extensão, em articulação com o mundo do trabalho e os segmentos sociais com ênfase na produção, desenvolvimento e difusão de conhecimentos científicos e tecnológicos [SILVA, 2009].

Muitos recursos são investidos para a manutenção e expansão da rede federal. O Ministério da Educação (MEC) conta, no Orçamento Geral da União, com o Programa Desenvolvimento da Educação Profissional e Tecnológica, que, no quadriênio 20082011, teve recursos empenhados da ordem de $\mathrm{R} \$ 11,5$ bilhões, conforme explicitado na Figura 1. Isso mostra a necessidade de promover um serviço de qualidade a sociedade brasileira no tocante a educação, o que está sensivelmente interligado a diminuição dos índices de evasão. 


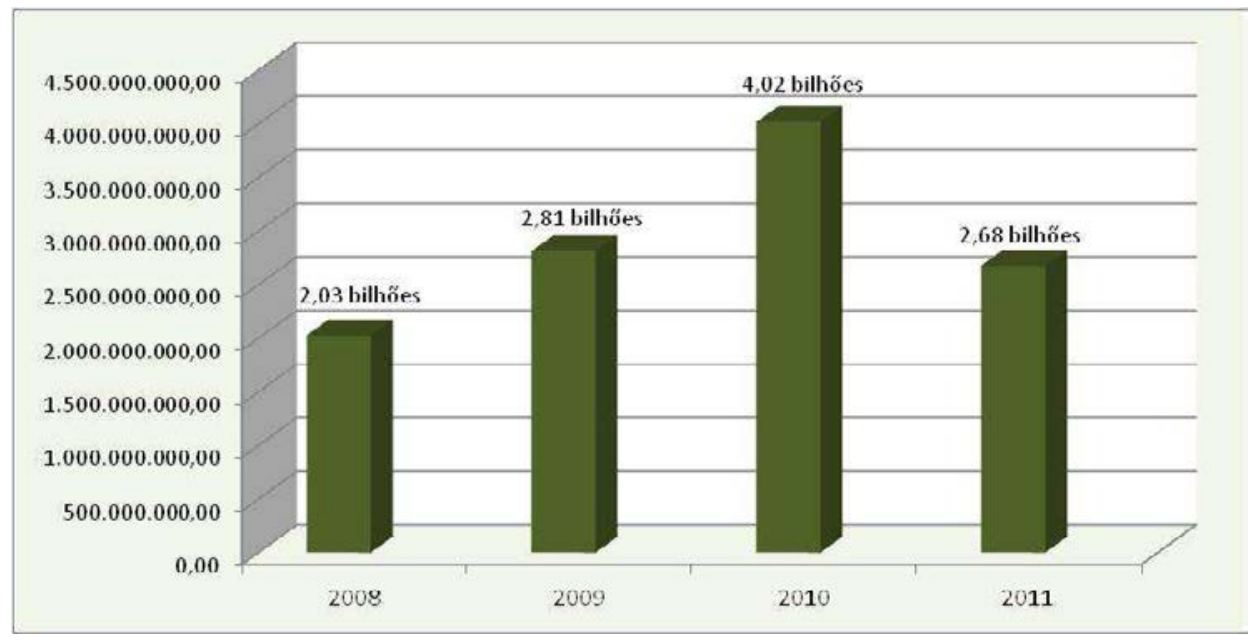

Figura 1 - Valores empenhados no Programa Desenvolvimento da Educação Profissional e Tecnológica, de 2008 a 2011. Fonte: [TCU, 2013].

A evasão representa um problema que alcança diferentes modalidades de ensino em maior ou menor medida. No Brasil, a educação profissional não foge a essa regra, sendo um importante vazamento que impede que boa parte dos alunos concluam seus respectivos cursos. A meta de $90 \%$ para a taxa de conclusão prevista no Projeto de Lei do Plano Nacional de Educação 2011-2020, ou mesmo da taxa de $80 \%$ para todas as modalidades de cursos ofertados pelos institutos prevista no Termo de Acordo de Metas, aparentemente, ainda é um ideal de longo-prazo. Quando se analisam as taxas de conclusão em nível nacional se situam em 46,8\% para o médio integrado, 37,5\% para o Proeja, 25,4\% para a Licenciatura, 27,5\% para o Bacharelado e 42,8\% para os cursos de tecnólogo. Em termos de estratégias de combate à evasão, será observado que muitas vezes a atuação dos campi, de determinado Instituto Federal, dá-se de forma isolada em relação aos demais [TCU, 2013].

Frente à relevância desse tema, o presente artigo discorre sobre a caracterização da evasão nos cursos de tecnologia da informação ofertados pelo Instituto Federal do Sertão Pernambucano no Campus do município de Floresta/PE. Propõem-se analisar de modo conjugado, três tipos de indicadores - de evasão, retenção e conclusão - para corretamente monitorar essa evasão.

\section{Metodologia}

São inúmeros os conceitos sobre pesquisa, posto que os estudiosos ainda não chegaram a um consenso sobre o assunto. Os critérios de classificação dos tipos de pesquisa variam de acordo com o enfoque dado pelo autor. A divisão obedece a interesses, condições, campos, metodologia, situações, objetivos, objetos de estudo etc [LAKATOS e MARCONI, 2008]. 
Observa-se que para avaliar a evasão escolar faz-se necessário avaliar não somente os indicadores da evasão escolar, mas, também o índice de retenção e de conclusão.

Para a execução desta pesquisa serão utilizados três indicadores:

- Evasão escolar - Taxa de alunos que abandonaram o curso

- Retenção escolar - Atraso no tempo de permanência no curso

- Conclusão escolar - Taxa de conclusão dos alunos

Este artigo utiliza a técnica do estudo de caso como a melhor estratégia para obtenção dos dados. O local escolhido foi o Campus Floresta do Instituto Federal de Educação, Ciência e Tecnologia do Sertão Pernambucano devido ao pioneirismo da pesquisa no campus que já possui 8 anos de funcionamento entre os anos de 2008 e 2016.

Coleta dos Dados - A coleta de dados compreende a aplicação dos instrumentos elaborados para esse fim, tendo em vista a importância do controle na sua execução visando à fidedignidade das informações [MARCONI e LAKATOS, 2008]. Para Yin (2004) o pesquisador que prima pela validade do constructo, deverá utilizar múltiplas fontes de evidência, a fim de se obter uma visão mais completa do contexto estudado. Para o autor podem ser consideradas fontes de evidência: a) documentos, b) registros em arquivos, c) entrevistas, d) observação direta, e) observação participante e; f) artefatos físicos. Suas vantagens de coleta, em geral, são: a) permite revisão; b) não foi criada como resultado do estudo de caso, e; c) contém referências e detalhes de um evento. Os registros em arquivos além dessas características são precisos e quantitativos.

Análise Qualitativa / Quantitativa - Os estudos estatísticos estão relacionados às situações que envolvem planejamentos, coleta de dados, organização de informações, análise das informações coletadas, interpretação e divulgação de forma clara e objetiva.

A coleta, a organização, a descrição dos dados, o cálculo e a interpretação de coeficientes pertencem à Estatística Descritiva, enquanto a análise e a interpretação dos dados, associados a uma margem de incerteza, ficam a cargo da Estatística Indutiva ou Inferencial, também chamada como a medida da incerteza ou métodos que se fundamentam na teoria da probabilidade [TRIOLA, 2011].

\section{A Evasão Escolar nos Cursos de Tecnologia da Informação no Instituto Federal do Sertão Pernambucano - Campus Floresta}

A evasão escolar nos cursos de tecnologia da informação no Instituto Federal do Sertão Pernambucano Campus Floresta/PE, apresenta índices muito elevados, chagando a 
quase $50 \%$ de alunos evadidos desde o início do funcionamento da instituição em 2008, de acordo com dados coletados na base de dados do (SISTEC).

Um índice de evasão escolar de 49,78\% é muito indesejável em qualquer curso que ocorra, merecendo ainda mais atenção quando se trata de cursos relacionados à tecnologia da informação, pois diante do desenvolvimento e do crescimento exponencial da tecnologia e da sua consequente necessidade de profissionais habilitados, este índice torna-se muito preocupante.

No gráfico constante na Figura 2, pode ser observada a diferença entre o percentual de alunos evadidos e de alunos concluídos ou em curso.

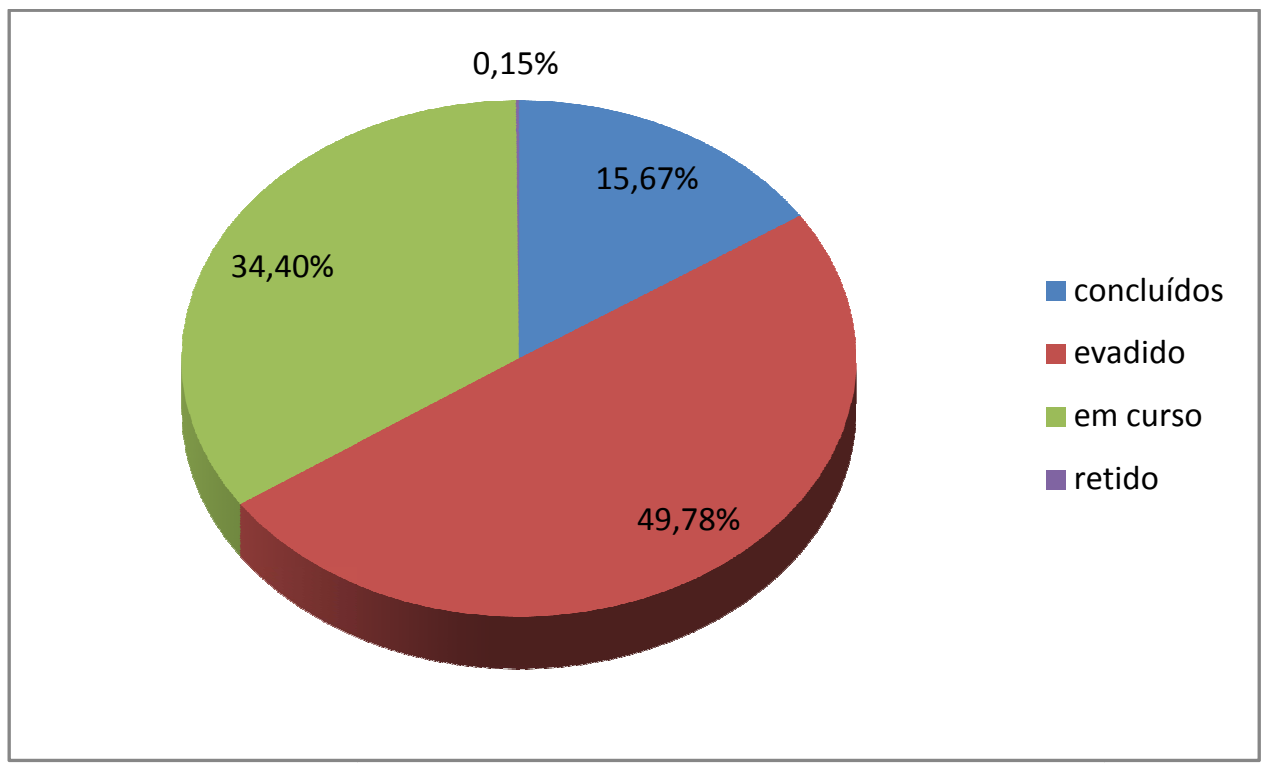

Figura 2 - Percentual de Alunos Evadidos.

De acordo com dados coletados na base de dados do (SISTEC), pode-se inferir que a taxa de conclusão é de $15,67 \%$ e a quantidade de alunos em curso é $34,40 \%$, caso todos os alunos em curso venham a concluir os seus respectivos cursos, o percentual de alunos concluintes será de $50,07 \%$ o que estará muito distante da meta estabelecida pelo Projeto de Lei do Plano Nacional de Educação 2011-2020. Estes números podem ser observados na Tabela 1.

O número total de evadidos (TV) nos cursos de tecnologia da informação no período considerado foi de $344(\mathrm{TV}=\mathrm{EV}+\mathrm{RT})$.

Tabela 1 - Números da Evasão nos Cursos de Tecnologia da Informação no Instituto Federal do Sertão Pernambucano Campus Floresta

STATUS

\begin{tabular}{ll}
\hline Concluídos (CO) & 108 \\
\hline Evadido (EV) & 343 \\
\hline Em Curso (EC) & 237 \\
\hline \hline
\end{tabular}


Diante destes números a fica evidente a importância de este assunto ser cada vez mais abordado em estudos.

\section{Resultados}

De acordo com os formulários aplicados, infere-se que os alunos apresentam um perfil de indecisão, conforme pode ser observado na Tabela 3, quando questionados a dúvida na escolha do curso a resposta é negativa em sua maioria, porém, quando questionados a respeito de um possível curso novo a ser ofertado pela instituição os cursos com maior índice de escolha são de areas bem díspares da area de tecnologia da informação, conforme pode ser observado no Figura 3.

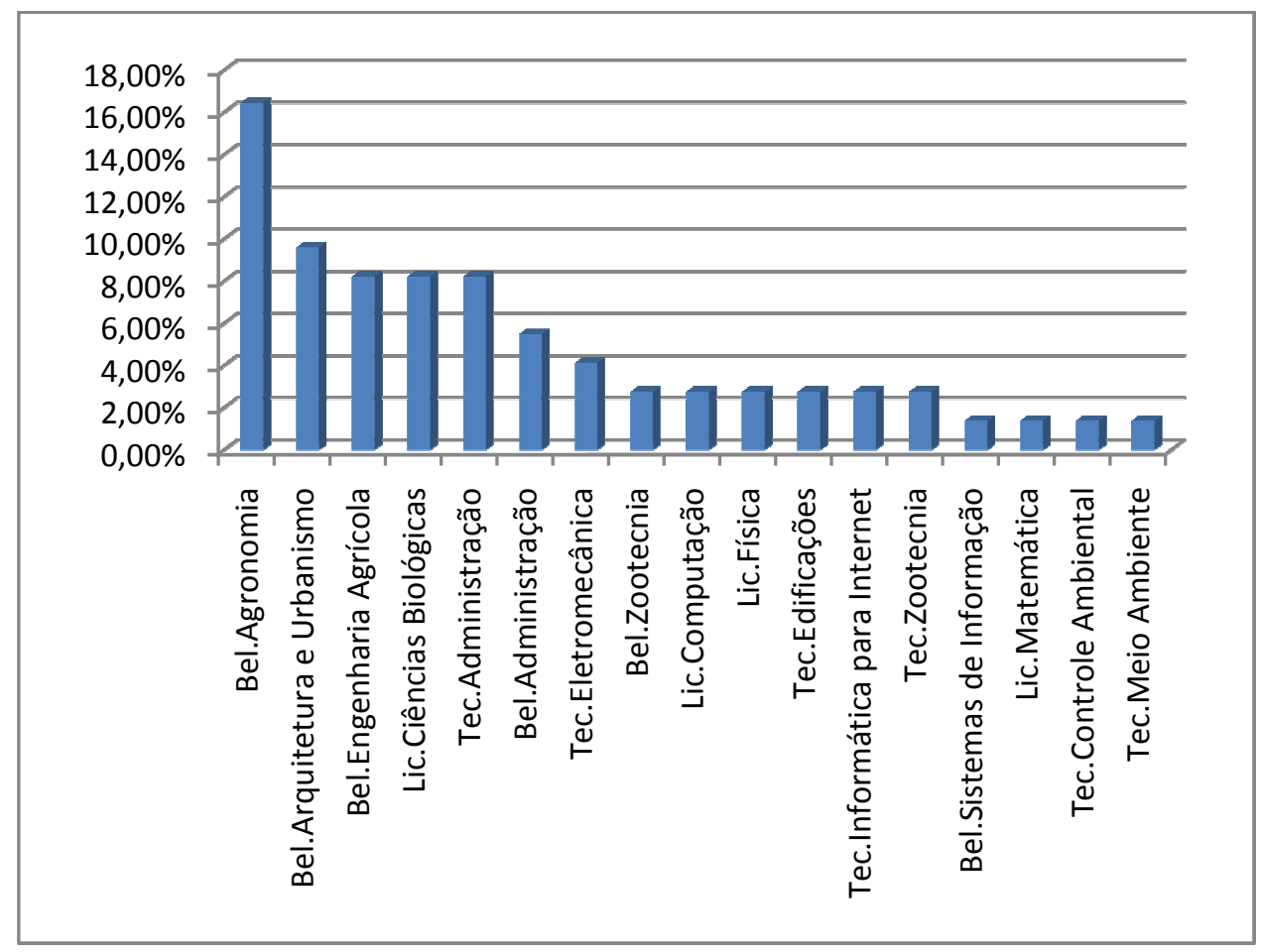

Figura 3 - Principais Cursos Escolhidos

Tabela 2 - Principais respostas escolhidas

\begin{tabular}{ll}
\hline PERGUNTA & Resposta mais escolhida \\
\hline Teve dúvida na escolha do curso & Não $(67,12 \%)$ \\
\hline Se a instituição fosse ofertar um novo curso & Bel. Agronomia $(16,44 \%)$ \\
\hline Teve aula de nivelamento antes de iniciar o curso & Não $(90,41 \%)$ \\
\hline Faria um outro curso & Sim, em outra area $(31,51 \%)$ \\
\hline Qualidade do ensino ofertado como fator motivador & Concordo Totalmente $(50,68 \%)$ \\
\hline
\end{tabular}




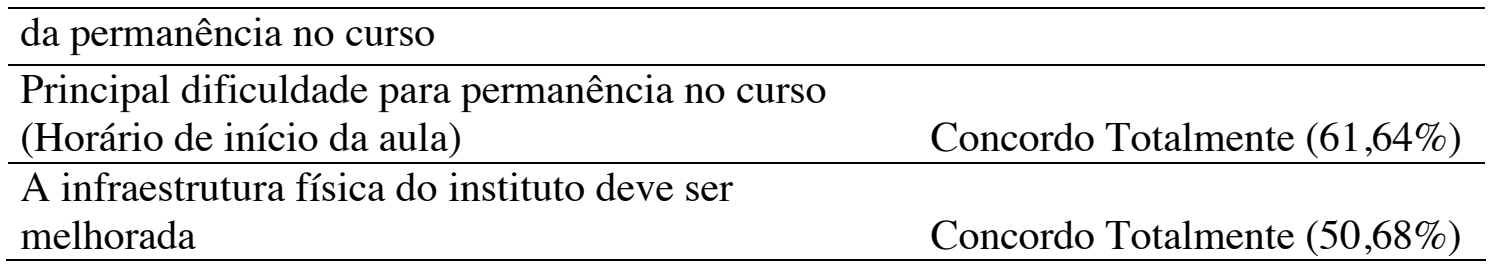

Com o avanço tecnológico que se vive nos dias atuais, um índice de evasão tão alto em cursos de tecnologia da informação torna-se muito preocupante, e medidas atenuadoras deste fenômeno devem ser colocadas em pauta com mais frequência. As novas tecnologias que aparecem no mercado de trabalho precisam de pessoas cada vez mais qualificadas e adaptadas as mesmas, para que possa haver um desenvolvimento socioeconômico mais efetivo.

\section{Considerações Finais}

De forma a enfrentar a evasão motivada por deficiências de formação, muitas instituições de Ensino Superior vêm implementando programas de nivelamento em conteúdos básicos para alunos ingressantes [SILVEIRA, et al. 2015].

Conforme pode ser observado na tabela 3, é possível inferir que a instituição não oferta cursos de nivelamento. Implantar programas de nivelamento para alunos ingressantes seria uma das soluções atenuadoras da evasão escolar, visto que os novos alunos ingressariam na instituição com um conhecimento mais aprimorado a respeito do curso em que tiver ingressando, evitando que os alunos tenham frustração logo no início da atividade acadêmica, levando-os posteriormente a evasão. A qualidade do curso oferecida pela instituição é positivamente avaliada pelos discentes, porém, a infraestrutura deve ser melhorada a fim de trazer um ambiente mais confortável.

\section{Referências}

CASARTELLI, A. O. et al. A evasão da educação superior: uma análise da produção de conhecimento no Brasil. In: LEITE, D.; FERNANDES, C.B. (Org.). Qualidade da educação superior: avaliação e implicações para o futuro da universidade. Porto Alegre: EDIPUCRS, 2012. p. 75-86.

CASTEL, R. As metamorfoses da questão social: uma crônica do salário. Petrópolis: Vozes, 1998.

GAIOSO, N. P. L. O fenômeno da evasão escolar na educação superior no Brasil. Universidade Católica de Brasília, 2005. Disponível em: http://www.scielo.br/scielo. php?pid=S1414-40772011000200007\&script=sci_arttext. Acesso em: 16/07/2015.

KINPARA, Daniel I.; DAN, Edival. O papel da universidade na formação de educadores a partir de profissionais de Ciências Agrárias. Lavras, MG, 1995. 62 f. 
Dissertação (Mestrado em Administração Rural) - Universidade Federal de Lavras. Lavras, MG, 1995.

MARCONI, Marina de Andrade; LAKATOS, Eva Maria. Pesquisa. In: Técnicas de Pesquisa: Planejamento, e Execução de Pesquisas, Amostragens e Técnicas de Pesquisa, Elaboração, Análise e Interpretação de Dados. 7 ed. São Paulo: Atlas, 2008. p. 1-25.

SILVA, Caetana Juracy (org.). Institutos Federais Lei 11.892, de 29/12/2008: Comentários e Reflexões. Natal: IFRN, 2009.

SILVA FILHO, R L Lobo et al. Evasão no Ensino Superior Brasileiro, Instituto Lobo para o desenvolvimento da educação, ciência e tecnologia. Cadernos de Pesquisa, v.37, n. 132, p.641-659. Set/Dez, 2007.

SILVEIRA, I. F. et al. O Desafio da Aprendizagem Adaptativa em Programas de Nivelamento para o Ensino Superior. In: CONGRESSO DA SOCIEDADE BRASILEIRA DE COMPUTAÇÃO, 35. 2015, Recife/PE.

TCU, TC 026.062/2011-9, Relatório de Auditoria, 2013. Auditoria operacional. Fiscalização de orientação centralizada. Rede Federal de Educação Profissional. Necessidade de aprimoramentos nas atuações relacionadas à evasão escolar, à interação com os arranjos produtivos locais e ao apoio à inserção profissional dos alunos. Carência de professores e de profissionais de laboratório. Ausência de instalações físicas adequadas em alguns Institutos Federais. Recomendações. Determinação. Comunicações.

TRIOLA, M. Introdução a estatística. 10. Ed. São Paulo: LTC, 2011.

YIN, Robert K. Case study research: design and methods. Thosands Oaks: SAGE, 1994. 